\title{
Нерезонансное обращение волнового фронта света в оптически возбужденных пленках ZnO
}

\author{
(c) А.Н. Грузинцев \\ Институт проблем технологии микроэлектроники Российской академии наук, \\ 142432 Черноголовка, Московская область, Россия \\ E-mail: gran@iptm.ru
}

Поступила в Редакцию 6 апреля 2020 г.

В окончательной редакции 12 апреля 2020 г.

Принята к публикации 12 апреля 2020 г.

\begin{abstract}
Теоретически и экспериментально показана возможность нерезонансного обращения волнового фронта света в возбужденной полупроводниковой среде. На эпитаксиальных пленках $\mathrm{ZnO}$ при комнатной температуре и накачке азотным лазером обнаружено индуцированное обращение волнового фронта света в видимой и инфракрасной областях спектра. Исследованы зависимости интенсивности сигнала обращения волнового фронта от энергии падающего фотона и интенсивности лазерной накачки. Предлагается объяснение эффекта: изменение поглощения и преломления света на индуцированных лазером свободных носителях в полупроводниковой среде.
\end{abstract}

Ключевые слова: люминесценция, обращение волнового фронта.

DOI: 10.21883/FTP.2020.08.49653.9406

\section{1. Введение}

В настоящее время наиболее перспективными для создания светоизлучающих структур в фиолетовой области спектра считаются оксид цинка и нитрид галлия (а также твердые растворы на его основе). Особенно важно получение данных о полупроводниковых материалах и структурах на их основе, обладающих монохроматическим свечением в экситонной или краевой области спектра. Для этого необходимо получение тонких пленок $\mathrm{ZnO}$ и $\mathrm{GaN}$ широкозонных полупроводников высокого кристаллического совершенства, так как собственные дефекты кристаллической решетки и неконтролируемые примесные доноры или акцепторы могут вызвать длинноволновый сдвиг люминесценции и появление широких неоднородно уширенных полос свечения в так называемой примесной области спектра.

Широкозонный полупроводниковый материал - оксид цинка $\left(E_{g}=3.37\right.$ эВ) обладает максимальной для своего класса соединений энергией связи экситона 60 мэВ [1], что позволяет наблюдать экситонное свечение до температур $\sim 550 \mathrm{~K}$. Благодаря высокой эффективности излучательной рекомбинации в пленках $\mathrm{ZnO}$ в ряде работ наблюдалась стимулированная люминесценция в ультрафиолетовой области 397 нм при возбуждении азотным лазером [2,3]. В этом случае происходило усиление света при излучательной рекомбинации электронно-дырочной плазмы (ЭДП) в сильно возбужденном оксиде цинка при мощном лазерном импульсном возбуждении. Особый интерес в последние годы изучение сильно возбужденных полупроводников получило в связи с явлением оптической бистабильтности. Это связано с тем, что межчастичные (электронов, дырок, экситонов) взаимодействия в кристалле приводят к существенной перестройке энергетического спектра полупроводника, обусловливающей большие нелинейности его оптических свойств. Данные механизмы нелинейности оптических свойств характеризуются в прямозонных полупроводниках субнаносекундными временами релаксации нелинейных изменений. Это обстоятельство выгодно отличает их от тепловых механизмов и позволяет надеяться, что созданные на их основе бистабильные элементы будут иметь субнаносекундные времена переключения.

Особый интерес вызывает такое нелинейное явление, как обращение волнового фронта (ОВФ) световой волны в возбужденной среде. Применение зеркал, обращающих волновой фронт в газовых лазерных резонаторах, рассматривали ряд авторов [4-6]. Достоинства такого типа зеркал состоят в том, что резонатор может самонастраиваться и ОВФ может исправлять искажения, вызванные усиливающей средой или оптическими элементами в резонаторе. Так как в этом случае падающая волна всегда отражается в строго обратном направлении, нет необходимости в строгой параллельности зеркал резонатора. В экспериментах по исследованию ОВФ [6] использовались мощности накачки $\sim 1.6 \cdot 10^{7} \mathrm{BT} / \mathrm{cm}^{2}$, а мощность отраженной волны составляла $\sim 2 \cdot 10^{-3}$ от мощности сигнальной волны (коэффициент отражения зеркала). Во всех выше указанных вариантах для обращения волнового фронта используется процесс трехволнового смешения в нелинейном кристалле или газообразной среде. Из-за этого зеркала ОВФ имеют большой объем, малый коэффициент отражения и не применимы для довольно миниатюрных полупроводниковых лазеров. В работе [7] теоретически и экспериментально показана возможность резонансного ОВФ в возбужденной полупроводниковой среде. На эпитаксиальных пленках $\mathrm{ZnO}$ при накачке азотным лазером было обнаружено обращение света для энергии фотонов, равной половине 
энергии излучательной рекомбинации свободных экситонов. Было предложено объяснение данного эффекта ОВФ: квадратичное взаимодействие световых и экситонных электромагнитных колебаний в возбужденной полупроводниковой среде.

Ранее теоретически и экспериментально была показана возможность нерезонансного обращения светового волнового фронта (ОВФ) в возбужденной полупроводниковой среде (на основе порошка $\mathrm{ZnO}$ ) при комнатной температуре и накачке импульсным азотным лазером [8]. Впервые было обнаружено обращение света при ступенчатом изменении диэлектрической проницаемости среды во время перехода Мотта и исследованы зависимости интенсивности сигнала ОВФ от угла его регистрации. Предложено объяснение наблюдаемого эффекта — это взаимодействие световых и электронно-дырочных плазменных колебаний в полупроводниковой среде.

Интересно исследовать эффект нерезонансного ОВФ при интенсивном оптическом возбуждении в пленках оксида цинка. В этом случае при комнатной температуре происходит ОВФ при образовании свободных экситонов или рекомбинации ЭДП в тонком слое $\sim 100$ нм. Цель данной работы заключалась в исследовании эффектов обращения волнового фронта и отражения электромагнитных волн на электронно-дырочной плазме в пленках $\mathrm{ZnO}$ в зависимости от энергии фотона падающего света и от интенсивности возбуждающего ультрафиолетового лазера.

\section{2. Эксперимент}

В работе использовались пленки $\mathrm{ZnO}$, нанесенные на сапфир основной ориентации (0001) методом электронно-лучевого высоковакуумного напыления на установке L-560 (Leubold Haereus). Толщина пленок составляла 0.5 мкм. Пленки $\mathrm{ZnO}$ имели высокое кристаллическое качество с осью роста, перпендикулярной поверхности [7]. В спектре их люминесценции при комнатной температуре превалировал пик экситонного свечения с максимумом 3.24 эВ. Спектры фотолюминесценции (ФЛ) пленок исследовались при возбуждении импульсным азотным лазером ЛГИ-505 с длительностью импульса 10 нсек, пиковой мощностью 15 КВт и длиной волны 337.1 нм. Схема установки, использованной для измерения сигнала обращения волнового фронта и фотолюминесценции на пленках оксида цинка, показана на рис. 1. Здесь важно отметить, что падающая на образец световая волна была от лампы накаливания „Нарва-100“, запитанной источником постоянного тока, и падала на образец под углом более 45 градусов, чтобы геометрически отраженный свет не попадал в регистрирующий монохроматор МДР-6. Свет лампы накаливания после прохождения через светосильный монохроматор МДР-12 был непрерывным во времени и имел спектральную полуширину не хуже 4 нм. Система регистрации спектра была настроена на частоту возбуждающего лазера

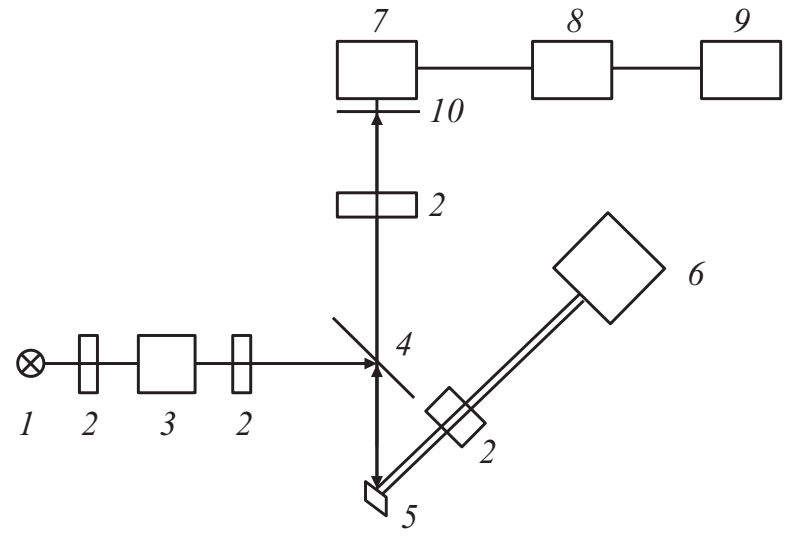

Рис. 1. Схема установки использованной для измерения фотолюминесценции и обращения волнового фронта света на пленках оксида цинка: 1 - источник света „Нарва-100“, 2 - линзы, 3 - монохроматор МДР-12, 4 - светоделитель, 5 - образец $\mathrm{ZnO}, 6$ - азотный лазер, 7 - монохроматор МДР-6, 8 - фотоумножитель ФЭУ-79 или ФЭУ-62, $9-$ система регистрации спектра и $10-$ светофильтр.

ЛГИ-505 и состояла из усилителя переменных сигналов „Unipan-237“ с выходом на компьютер. Образец оксида цинка находился при комнатной температуре и был сориентирован так, чтобы электромагнитные колебания лазерной и световой волны имели составляющие вдоль оси роста пленки. Лазерный пучок фокусировался на поверхности пленки в пятно диаметром < 100 мкм, что позволяло получать максимальную плотность мощности накачки $\sim 10^{8} \mathrm{BT} / \mathrm{cm}^{2}$. Совмещение светового и лазерного пятна на образце контролировалось с помощью оптического микроскопа. В качестве светоделителя (рис. 1) использовалась обычная кварцевая пластина. При регистрации спектров обращенного сигнала и люминесценции пленки использовались светофильтры ЖС-12 и С3С-23, соответственно, для удаления паразитных сигналов второго порядка двойного монохроматора МДР-6 в регистрируемых спектрах.

\section{1. Теория}

Пусть свет распространяется в полупроводниковой среде, диэлектрическая $\varepsilon$ (или магнитная $\mu$ ), проницаемость которой в какой-то момент времени $t_{1}=0$, плавно или ступенчато (рис. 2) изменяется от величины $\varepsilon_{1}\left(\mu_{1}\right)$ до величины $\varepsilon_{2}\left(\mu_{2}\right)$. Вообще говоря, два фундаментальных явления могут изменять оптические свойства полупроводника под действием мощного импульса лазера с энергией кванта больше ширины запрещенной зоны и при концентрации возбуждаемых электроннодырочных пар, близкой к порогу Мотта. Во-первых, это перенормировка электронного спектра вследствие экранирования кулоновского взаимодействия. Вторым важным явлением является возникновение плазменных колебаний и их взаимодействие с оптическими фоно- 


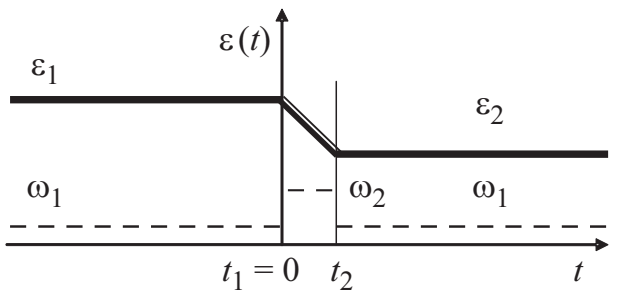

Рис. 2. Изменение во времени диэлектрической проницаемости среды и эффективной частоты света в ней под действием УФ лазерного импульса в момент времени $t_{1}=0$.

нами, которое приводит к перенормировке фононного спектра - образованию смешанных фонон-плазмонных мод. Изменение оптических постоянных различных полупроводников под действием мощных лазерных импульсов наблюдалось методами фотолюминесценции и комбинационного рассеяния света. При этом характерные времена изменений $-\varepsilon$ (рис. 2) находились в пикосекундном диапазоне, приводили к появлению производной по времени в дипольном моменте среды, а значит, и к появлению новых волн электромагнитного излучения - ОВФ в момент переключения. Далее мы покажем, что непрерывность волновой функции света и ее производной во времени позволяет определить амплитуду и временны́е характеристики ОВФ света для разных длин волн.

Уравнения Максвелла световой волны в полупроводниковой среде (рис. 2) принимают вид волнового уравнения [9]:

$$
\Delta E-\varepsilon \mu / c^{2} \cdot d^{2} E / d^{2} t=0
$$

где $E(x, t)$ - волновой вектор электрического поля световой волны, а $\varepsilon(t), \mu$ - диэлектрическая и магнитная проницаемость среды и $c-$ скорость света. Для простоты будем искать решение волнового уравнения в виде однородных волн, движущихся вдоль оси $X$ : $E=E_{0} \exp (i \omega t-i k x n)$. При этом будем рассматривать изменение во времени амплитуды и частоты электромагнитной волны в какой-либо фиксированной точке пространства $X=x_{0}$. Разложим в ряд Тейлора изменение по времени показателя преломления среды $n(t)=(\varepsilon \mu)^{1 / 2}=n_{1}+d n / d t \cdot t+\ldots$ и решение волнового уравнения с учетом комплексно-сопряженной (К.С.) части примет вид:

$$
E=E_{0} \exp \left(i \omega t-i k x_{0} \cdot d n / d t \cdot t-i k x_{0} \cdot n_{1}\right)+\text { K.C. }
$$

Тогда волновое уравнение (1) для временно́й составляющей $E(\omega, t)$ световой волны после дифференцирования в Лапласиане примет вид:

$$
d^{2} E / d^{2} t+k^{2} c^{2} /(\varepsilon \mu) \cdot E=0
$$

Здесь от времени зависит также диэлектрическая проницаемость, изменяющаяся по ступенчатому закону в мо- мент времени $t_{1}=0$ перехода Мотта в полупроводниковой среде (рис. 2). Пусть до перехода (при $t<0)$ диэлектрическая проницаемость была $\varepsilon_{1}$ и тогда решение уравнения (2) имеет вид: $E_{1}=\exp \left(i \omega_{1} t\right)$, где $\omega_{1}=k c / n_{1}$. После изменения диэлектрической проницаемости среды (при $t>0)$ решение уравнения (2) следует искать в виде волн другой частоты: $E_{2}=A \exp \left(i \omega_{2} t\right)+B \exp \left(-i \omega_{2} t\right)$, где $\omega_{2}=\omega-k x_{0} \cdot d n / d t$. Постоянные $A$ и $B$ определяются из условия непрерывности во времени световой волны и ее производной при $t_{1}=0$ (рис. 2), что дает соотношения:

$$
1=A+B, \quad \omega_{1}=\omega_{2} A-\omega_{2} B
$$

Откуда имеем выражения для амплитуд прошедшей и отраженной волн:

$$
A=\left(\omega_{1}+\omega_{2}\right) / 2 \omega_{2} \quad \text { и } \quad B=\left(\omega_{2}-\omega_{1}\right) / 2 \omega_{2} .
$$

Таким образом, в момент переключения $\left(t_{1}-t_{2}\right)$ диэлектрической проницаемости среды световая волна в среде с учетом пространственной части имеет вид

$$
E_{2}=A \exp \left(i \omega_{2} t-i k x\right)+B \exp \left(-i \omega_{2} t-i k x\right),
$$

где $\omega_{2}=\omega_{1}-k x_{0} \cdot d n / d t$, а постоянные $A$ и $B$ определяются выражением (4). При этом видно, что если первое слагаемое представляет волну, двигающуюся в положительном направлении оси $X$, то второе дает обращенную волну, двигающуюся навстречу первой. Происходит обращение волнового фронта света в среде с изменяющимися в момент падения возбуждающего лазерного импульса оптическими характеристиками. Амплитуда обращенной световой волны, согласно (4), $B=-k x 0 /\left(2 \omega_{2}\right) d n / d t$ пропорциональна производной изменения показателя преломления и толщине слоя ( $100 \mathrm{Hм})$, в котором происходит это изменение. Если временны́х изменений оптических параметров $\varepsilon(t)$ среды нет (при малой интенсивности импульсного лазера или при непрерывном лазерном возбуждении), то ОВФ не происходит. Таким образом, обращенная волна в нашем случае (рис. 2) возникает в момент времени $t_{1}$, а заканчивается в момент времени $t_{2}$.

\section{3. Результаты и их обсуждение}

На рис. 3 показаны кривые свечения образцов $\mathrm{ZnO}$ при различных мощностях оптической накачки от 70 КВт/см² (кривая 1) до $70 \mathrm{MBT} / \mathrm{cm}^{2}$ (кривая 7). Видно, что при малых плотностях мощности возбуждения от 70 до $2500 \mathrm{KBT} / \mathrm{cm}^{2}$ (кривые $1-3$ ) в ФЛ пленок $\mathrm{ZnO}$ превалирует полоса свободных экситонов, максимум которой незначительно сдвигается в длинноволновую сторону от 385 до $386 \mathrm{Hм} \mathrm{с} \mathrm{увеличением} \mathrm{мощности}$ накачки на 3 порядка величины. Характер зависимости площади под кривой свечения и ширины экситонной линии люминесценции на полувысоте от интенсивности 


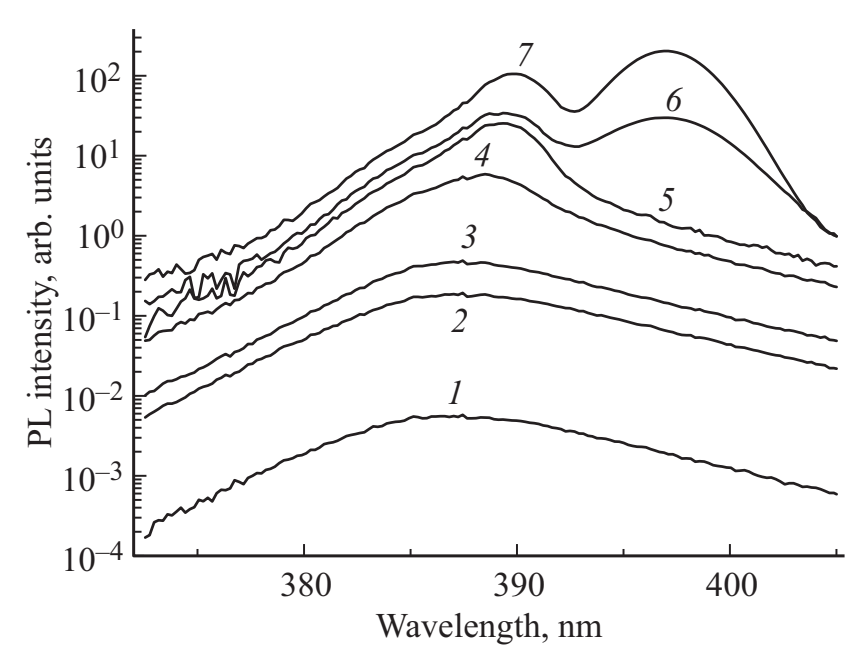

Pис. 3. Спектры фотолюминесценции пленок $\mathrm{ZnO}$ при различных интенсивностях возбуждающего азотного лазера: $70 \mathrm{KBT} / \mathrm{cm}^{2}(1), 600 \mathrm{KBT} / \mathrm{cm}^{2}(2), 2.5 \mathrm{MBT} / \mathrm{cm}^{2} \quad$ (3), $8 \mathrm{MBT} / \mathrm{cm}^{2} \quad(4), \quad 22 \mathrm{MBT} / \mathrm{cm}^{2} \quad(5), \quad 33 \mathrm{MBT} / \mathrm{cm}^{2} \quad$ (6) и $70 \mathrm{MBT} / \mathrm{cm}^{2}(7) . T=300 \mathrm{~K}$.

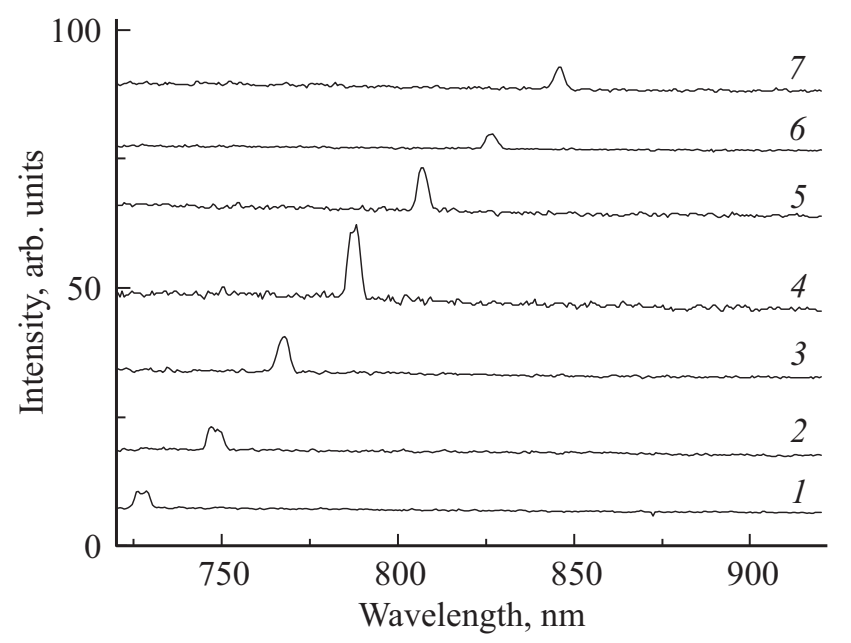

Рис. 4. Спектры сигнала ОВФ пленок $\mathrm{ZnO}$ при интенсивности возбуждающего азотного лазера $70 \mathrm{MB} / \mathrm{cm}^{2}$ и длине волны падающего света, нм: 727 (1), 747 (2), 770 (3), 788 (4), 807 (5), 825 (6) и $845(7) . T=300 \mathrm{~K}$.

лазерного возбуждения свидетельствуют о ее спонтанном характере. Далее при мощности накачки более $8 \mathrm{MBT} / \mathrm{cm}^{2}$ (кривые 4-7) в спектре ФЛ появляется линия стимулированной люминесценции с максимумом 389 нм (так называемая $P$-полоса), обусловленная рассеянием двух свободных электронов с излучением одного из них [10]. В случае стимулированной люминесценции рост площади был сверхлинейным с явно выраженным пороговым значением, а ширина линии, наоборот, уменьшалась для надпороговых плотностей мощности. При интенсивностях возбуждения 33 и 70 МВт/см ${ }^{2}$ (кривые 6 и 7) в люминесценции появляется $N$-пик с мак- симумом 397 нм, связанный со стимулированной рекомбинацией электронно-дырочной плазмы оксида цинка.

Теперь одновременно с импульсным возбуждением азотным лазером (плотность мощности $70 \mathrm{MBT} / \mathrm{cm}^{2}$ ) направим на образец непрерывный по времени световой поток из инфракрасной спектральной области с длиной волны фотона от 727 до 845 нм, равной половине энергии излучательной рекомбинации ЭДП в оксиде цинка. В момент лазерного импульса возникает обращение волнового фронта непрерывной подсветки на плазменных колебаниях пленки (рис. 4). В этом случае перед регистрирующим монохроматором МДР-6 ставился светофильтр ЖС-12, который не пропускал не только рассеянный свет лазера 337.1 нм, но и сигнал люминесценции пленки ZnO. Это делалось для устранения возможного в монохроматоре 2-го порядка линий люминесценции. Мы видим, что при такой мощности азотного лазера обращенный световой сигнал, повторяющий спектр падающего непрерывного света, присутствует для всех ИК длин волн. Однако при приближении длины волны фотона к 788 нм (кривая 4), равной удвоенной длине волны рекомбинации ЭДП, интенсивность обращенной волны резко возрастает. Метод регистрации сигнала говорит о том, что в отличие от падающей волны обращенная имеет импульсный характер с частотой возбуждающего лазера. Спектральная полуширина сигнала ОВФ совпадает с шириной падающей световой волны, а интенсивность волны зависит от ее спектрального положения и мощности возбуждающего азотного лазера.

На рис. 5 построены зависимости интенсивности обращенной волны в максимуме ее спектрального положения для разных мощностей азотного лазера. Видно, что сигнал ОВФ имеет два максимума интенсивности с длиной волны 780 и 795 нм для мощности лазера 33 и $70 \mathrm{MB} / \mathrm{cm}^{2}$ (кривые 2 и 3) при энергии падающих фотонов, совпадающей с половиной энергии пиков ре-

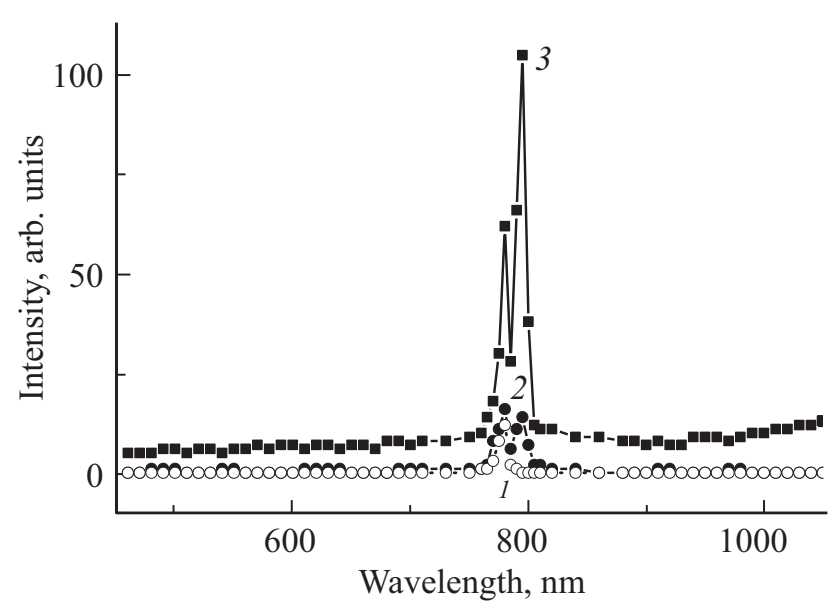

Рис. 5. Интенсивность максимума сигнала ОВФ пленок $\mathrm{ZnO}$ в зависимости от длины волны падающего света для различной мощности возбуждающего азотного лазера, МВт/см ${ }^{2}: 22$ (1), 33 (2) и $70(3) . T=300 \mathrm{~K}$. 
комбинации рассеянных экситонов и ЭДП в оксиде цинка. Кроме данного резонансного ОВФ, для максимальных интенсивностей лазера имеется на порядок меньшее нерезонансное обращение волнового фронта для всех длин волн, возрастающее в инфракрасной области спектра (кривая 3). Для мощности азотного лазера $22 \mathrm{MBT} / \mathrm{cm}^{2}$ (кривая 1) нерезонансная составляющая отсутствует, а имеется лишь резонансный пик 780 нм. В работе [7] показано, что аналогичное резонансное ОВФ происходило на свободных экситонах в оксиде цинка. В нашем случае еще происходит резонансное ОВФ на электромагнитных колебаниях взаимодействующих экситонов и ЭДП, также обладающих нулевым волновым вектором. Отметим, что, согласно приведенным в работе [7] теоретическим выкладкам, для сред с квадратичной оптической нелинейностью может возникать резонансное обращение волнового фронта при энергии фотонов падающего света, равной половине энергии электромагнитных колебаний-поляритонов в среде с нулевым волновым вектором (экситоны, плазмоны, фононы или примесные состояния). При этом интенсивность резонансной обращенной волны пропорциональна интенсивности падающего света и интенсивности стоячей волны электромагнитных колебаний поляритонов.

Интересно отметить, что для случая оксида цинка, в процессе образования ЭДП, имеется также сигнал ОВФ света в нерезонансных видимой и инфракрасной (ИК) областях спектра (рис. 4 и 5). При этом интенсивность сигнала нерезонансного обращения волнового фронта на порядок меньше интенсивности резонансного ОВФ (рис. 4, кривые 1, 2, 6 и 7) и увеличивается с увеличением длины волны падающего непрерывного света в ИК спектральную область (рис. 5, кривая 3). Остановимся подробнее на зависимости сигналов нерезонансного ОВФ с длиной волны 600 нм и резонансного ОВФ с длинами волн 780 и 795 нм от мощности накачки импульсного азотного лазера (рис. 6). Использование калиброванных поглотителей света позволило нам получить набор мощностей от 0.070 до $70 \mathrm{MBT} / \mathrm{cm}^{2}$ ультрафиолетового возбуждения пленок $\mathrm{ZnO}$. Видно, что интенсивность сигнала обращения волнового фронта с длиной волны 780 нм (рис. 6, кривая 4) растет нелинейно с интенсивностью УФ-накачки > 8000 КВт/см ${ }^{2}$ аналогично росту фотолюминесценции рассеянных электронов с длиной волны 389 нм (рис. 6, кривая 1). Рост сигналов ОВФ с длинами волн 600 и 795 нм (кривые 3 и 5) начинается с больших мощностей накачки $33 \mathrm{MBT} / \mathrm{cm}^{2}$ аналогично росту фотолюминесценции ЭДП с длиной волны 397 нм (рис. 6, кривая 2). При такой высокой интенсивности накачки происходит переход Мотта в газе свободных экситонов с образованием множества свободных носителей заряда (электронов и дырок), что видно по трансформации спектров свечения пленок (рис. 3). Именно за счет увеличения концентрации свободных носителей в пленках $\mathrm{ZnO}$ при возбуждении УФ лазерным импульсом измененяется показатель преломления и появляется сигнал нерезонансного ОВФ

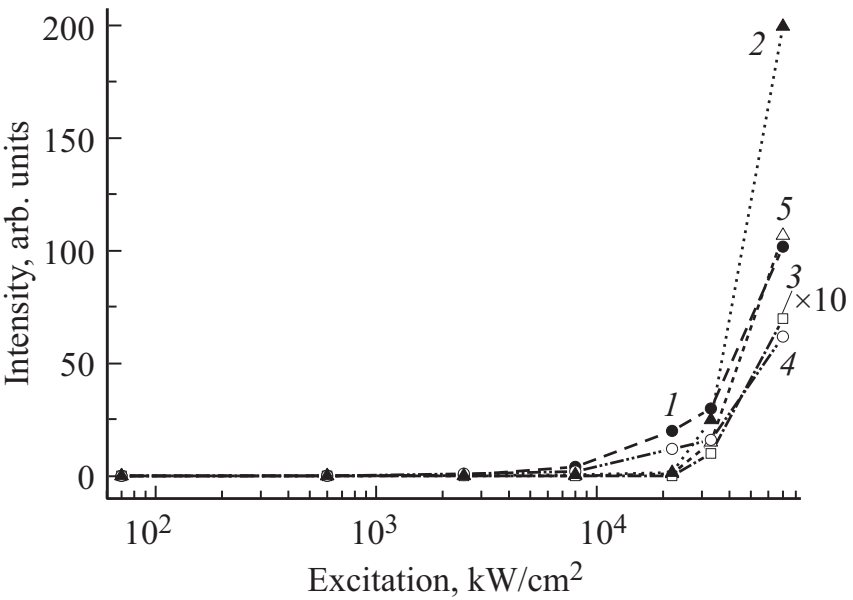

Рис. 6. Зависимость сигнала фотолюминесценции в максимуме полос 389 (1) и 397 нм (2), а также сигнала модулированного ОВФ пленок $\mathrm{ZnO}$ для длин волн отраженного света, нм: 600 (3), 780 (4) и 795 (5) от плотности возбуждения азотного лазера. $T=300 \mathrm{~K}$.

в видимой или инфракрасной области спектра (рис. 4 и 5). Происходит модуляция непрерывного света от лампы накаливания, прошедшего через монохроматор, с частотой азотного лазера. Этот модулированный или индуцированный мощным лазером сигнал ОВФ был зарегистрирован в геометрии обратного отражения от поверхности пленок оксида цинка. В таком полупроводнике $(\mathrm{ZnO})$ возбужденные носители существуют как раз в свободном виде при комнатной температуре измерений из-за перехода Мотта. Анализ выражений (3) и (4) показывает увеличение амплитуды модуляции коэффициента отражения с увеличением интенсивности УФ-возбуждения (увеличение концентрации свободных носителей) и с увеличением длины волны падающего света. Это хорошо согласуется с данными измерений сигнала модулированного ОВФ для разных мощностей оптической УФ-накачки и для разных длин волн падающего света (рис. 4-6). Также наблюдается рост интенсивности сигнала модулированного отражения в ИК-области спектра по сравнению с видимой областью спектра.

Отметим также, что сравнение эффективности нерезонансного обращения волнового фронта, индуцированного ультрафиолетовым лазером, в пленках нитрида галлия и оксида цинка [11] при одном и том же уровне мощного оптического возбуждения явно не в пользу последнего. В оксиде цинка при малой интенсивности накачки из-за большой энергии связи возбужденных носителей в свободный экситон при комнатной температуре в спектрах ФЛ превалирует экситонное свечение, a не излучение ЭДП (рис. 3). Поэтому практически все возбужденные лазером носители присутствуют в пленках оксида цинка не в свободном виде, а в виде свободных экситонов. Однако последние электрически нейтральны и не дают вклад в проводимость материала 
и в поглощение света за счет проводимости среды, которую мы и модулируем азотным лазером в данном эксперименте.

\section{4. Заключение}

Таким образом, обнаруженное нами нерезонансное обращение волнового фронта света от поверхности пленок $\mathrm{ZnO}$ при больших мощностях ультрафиолетовой импульсной накачки можно объяснить процессами генерации свободных носителей или электронно-дырочной плазмы. При этом с ростом мощности накачки также происходит появление линии люминесценции ЭДП, локальное увеличение фотопроводимости и связанное с этим увеличение поглощения света на свободных носителях. Интенсивность ОВФ света также возрастает в месте падения лазерного луча при временно́м изменении диэлектрической проницаемости среды. Сверхлинейная зависимость (рис. 6) интенсивности индуцированного ОВФ от интенсивности возбуждения оксиди цинка обусловливается ее зависимостями (3) и (4) от производной показателя преломления и толщины возбужденного слоя. Для получения сигнала нерезонасного ОВФ в оксиде цинка требуется образование не свободных экситонов, а свободных электронов и дырок при большой интенсивности накачки. Если учесть, что лазерное излучение при зона-зонном возбуждении поглощается в субмикронном (0.1 мкм) поверхностном слое, то легко получить высокую плотность ЭДП в тонких пленках полупроводника. Главное для нерезонансного ОВФ возбуждающий импульс должен быть достаточно мощным и коротким для сильного временно́го изменения диэлектрической проницаемости среды.

\section{Благодарности}

Автор выражает благодарность В.Т. Волкову за предоставление пленок оксида цинка.

\section{Конфликт интересов}

Авторы заявляют, что у них нет конфликта интересов.

\section{Список литературы}

[1] Y. Chen, D.M. Bagnall, Z. Zhu, T. Sekiuchi, K. Park. J. Cryst. Growth, 181, 165 (1997).

[2] J. Chen, T. Fujita. Jpn. J. Appl. Phys., 41, L203 (2002).

[3] А.Н. Грузинцев, В.Т. Волков, Л. Бартхоу, П. Беналул. ФТП, 36 (6), 741 (2002).

[4] P.A. Belanger, A. Hardy, A.E. Seigman. Appl. Optics, 19, 602 (1980).

[5] J.F. Lam, W.P. Brown. Optics Lett., 5, 61 (1980).

[6] D.M. Bloom, G.C. Bjoklund. Appl. Phys. Lett., 31, 592 (1977).

[7] А.Н. Грузинцев, В.Т. Волков. ФТП, 38, 543 (2004).

[8] А.Н. Грузинцев. ФТП, 43, 289 (2009).
[9] Ф. Качмарек. Введение в физику лазеров (М., Мир, 1981).

[10] Y.G. Wang, N. Ohashi, Y. Wada, I. Sakaguchi, T. Ohgaki, H. Haneda. J. Appl. Phys., 100, 023524 (2006).

[11] А.Н. Грузинцев, А.Н. Редькин. ФТП, 59, 26 (2019).

Редактор А.Н. Смирнов

\section{Nonresonant phase conjugation of light in the $\mathrm{ZnO}$ thin film under optical pumping}

\author{
A.N. Gruzintsev \\ Institute of Microelectronics Technology Problems \\ of Russian Academy of Sciences, \\ 142432 Chernogolovka, Russia
}

\begin{abstract}
The opportunity of the nonresonant phase conjugation of light in the excited semiconductor was shown theoretical and experimental. The induced nonresonant phase conjugation of light in the visibal and infrared spectral region was detected on the $\mathrm{ZnO}$ epitaxial films at room temperature by nitrogen laser pumping. The dependences of the nonresonant phase conjugation signal intensity on its photon energy and on the intensity of laser pumping were investigated. This effect explanation was given: $\mathrm{c}$ hange of absorption and refraction of the light on the laser induced free carriers in the semiconductor.
\end{abstract}

